\title{
Rapid Accurate Identification of Tuberculous Meningitis Among South African Children Using a Novel Clinical Decision Tool
}

DOI:

10.1097/INF.0000000000001726

\section{Document Version}

Accepted author manuscript

Link to publication record in Manchester Research Explorer

Citation for published version (APA):

Goenka, A., Jeena, P., Mlisana, K., Solomon, T., Stephenson, R., Verma, A., Dhada, B., \& Griffiths, M. (2018). Rapid Accurate Identification of Tuberculous Meningitis Among South African Children Üsing a Novel Clinical Decision Tool. Pediatric Infectious Disease Journal, 37(3). https://doi.org/10.1097/INF.0000000000001726

\section{Published in:}

Pediatric Infectious Disease Journal

\section{Citing this paper}

Please note that where the full-text provided on Manchester Research Explorer is the Author Accepted Manuscript or Proof version this may differ from the final Published version. If citing, it is advised that you check and use the publisher's definitive version.

\section{General rights}

Copyright and moral rights for the publications made accessible in the Research Explorer are retained by the authors and/or other copyright owners and it is a condition of accessing publications that users recognise and abide by the legal requirements associated with these rights.

\section{Takedown policy}

If you believe that this document breaches copyright please refer to the University of Manchester's Takedown Procedures [http://man.ac.uk/04Y6Bo] or contact uml.scholarlycommunications@manchester.ac.uk providing relevant details, so we can investigate your claim.

\section{OPEN ACCESS}


The Pediatric Infectious Disease Journal Publish Ahead of Print

DOI: 10.1097/INF.0000000000001726

\section{Rapid Accurate Identification of Tuberculous Meningitis Among South African Children}

\section{Using a Novel Clinical Decision Tool}

Anu Goenka, MRCPCH ${ }^{1,2,3}$, Prakash M. Jeena, $\mathrm{PhD}^{4}$, Koleka Mlisana, $\mathrm{PhD}^{5,6}$, Tom Solomon,

$\mathrm{PhD}^{7,8}$, Kevin Spicer, $\mathrm{PhD}^{3,4}$, Rebecca Stephenson, $\mathrm{MRCPCH}^{3}$, Arpana Verma, $\mathrm{PhD}^{2,9}$, Barnesh

Dhada, FCPaed (SA) ${ }^{3,4}$, and Michael J. Griffiths, $\mathrm{PhD}^{7,10}$

Corresponding Author Dr. Anu Goenka MRCPCH

Manchester Collaborative Centre for Inflammation Research, University of Manchester

Manchester M13 9NT, UK, Tel: +44 1612755494 Fax: +44 1612755600

anu.goenka@manchester.ac.uk

Abbreviated Title: Rapid Clinical Decision Tool to Diagnose Childhood TB Meningitis

Running Head: Rapid Diagnosis of Childhood TB Meningitis

1. Manchester Collaborative Centre for Inflammation Research, University of Manchester, UK

2. Manchester Academic Health Sciences Centre, University of Manchester, UK

3. Department of Paediatrics and Child Health, Pietermaritzburg Metropolitan Hospitals

Complex, South Africa

4. Department of Paediatrics and Child Health, University of KwaZulu-Natal, South Africa

5. Department of Microbiology, National Health Laboratory Service, South Africa

6. School of Laboratory Medicine and Medical Sciences, University of KwaZulu-Natal, South Africa

7. Health Protection Research Unit in Emerging and Zoonotic Infections, Institute of Infection and Global Health, University of Liverpool, UK 
8. Walton Centre NHS Foundation Trust, UK

9. Centre for Epidemiology, Institute of Population Health, University of Manchester, UK

10. Department of Neurology, Alder Hey Children's NHS Trust, UK

\section{Conflicts of Interest and Sources of Funding}

The authors declare no conflict of interest. Dr. Anu Goenka was supported by a Royal College of Physicians Thomas Watts Eden Fellowship. The study was supported by the National Institute for Health Research Health Protection Research Unit (NIHR HPRU) in Emerging and Zoonotic Infections at the University of Liverpool in partnership with Public Health England (PHE) and Liverpool School of Tropical Medicine (LSTM). The views expressed are those of the author(s) and not necessarily those of the NHS, the NIHR, the Department of Health or Public Health England. 


\section{ABSTRACT}

Introduction: Early diagnosis of tuberculous meningitis (TBM) is crucial to achieve optimum outcomes. There is no effective rapid diagnostic test for use in children. We aimed to develop a clinical decision tool to facilitate the early diagnosis of childhood TBM.

Methods: Retrospective case control study across 7 hospitals in KwaZulu-Natal, South Africa (2010-2014). We identified the variables most predictive of microbiologically confirmed TBM in children ( 3 months- 15 years) by univariate analysis. These variables were modelled into a clinical decision tool and performance tested on an independent sample group.

Results: Of 865 children with suspected TBM, 3\% (25) were identified with microbiologically confirmed TBM. Clinical information was retrieved for 22 microbiologically confirmed cases of TBM and compared with 66 controls matched for age, ethnicity, sex and geographical origin. The 9 most predictive variables among the confirmed cases were used to develop a clinical decision tool (CHILD TB LP): altered Consciousness; caregiver HIV infected; Illness length >7 days; Lethargy; focal neurological Deficit; failure to Thrive; Blood/serum sodium <132mmol/L; CSF $>10$ Lymphocytes $\times 10 * 6 / \mathrm{L}$; CSF Protein $>0.65 \mathrm{~g} / \mathrm{L}$. This tool successfully classified an independent sample of 7 cases and 21 controls with a sensitivity of $100 \%$ and specificity of $90 \%$.

Conclusion: The CHILD TB LP decision tool accurately classified microbiologically confirmed TBM. We propose that CHILD TB LP is prospectively evaluated as a novel rapid diagnostic tool for use in the initial evaluation of children with suspected neurological infection presenting to hospitals in similar settings.

Key Words: Tuberculous meningitis; children; diagnosis; case definition; scoring systems 


\section{INTRODUCTION}

Tuberculous meningitis (TBM) is a devastating illness that disproportionately affects young children. ${ }^{1-3}$ It is the most common cause of meningitis affecting children in South Africa. ${ }^{4}$ Approximately $50 \%$ of cases result in death or disability. ${ }^{1-3,5,6}$ The early diagnosis and treatment of TBM is important to ensure optimum outcomes. ${ }^{2,5-7}$ Its non-specific clinical presentation means that treatment is often only initiated after irreversible damage has occurred. ${ }^{2,6,8}$ The current standard diagnostic test is cerebrospinal fluid (CSF) culture which can take weeks, and has been reported with varying degrees of sensitivity. ${ }^{9-11}$ The use of Xpert MTB/RIF (Cepheid, Sunnyvale, California) on CSF samples offers a more rapid diagnosis of TBM, but it has also been reported to have variable sensitivity. ${ }^{12}$ Only 4 of 22 high-burden developing countries have recommended the use of Xpert MTB/RIF on CSF samples largely due to resource constraints. ${ }^{13}$ Several studies have proposed clinical decision tools that facilitate the early diagnosis of TBM in adults, but few studies have reported individual clinical variables that are predictive of TBM in children. ${ }^{3,7,14,15}$ The utility of adult decision tools in pediatric clinical presentations is limited because of the inclusion of variables such as headache, which are difficult to assess in infants and young children. ${ }^{16}$ We set out to develop a rapid clinical decision tool based on the most commonly recorded and predictive markers of childhood TBM. Predictive variables were identified using information collected retrospectively from clinical records from a cohort of children with suspected TBM presenting to hospitals in KwaZulu-Natal (KZN), the province of

South Africa most heavily burdened by TB with an incidence of 922 cases per 100,000 in 2013. ${ }^{17}$ Predictive variables were modelled into a rapid clinical decision tool, which we propose for use in the initial evaluation of children with suspected central nervous system (CNS) infection presenting to hospitals in similar settings. 


\section{METHODS}

A retrospective case-control study was performed across the 7 hospitals with the highest number of microbiologically proven childhood TBM cases in KZN: Addington Hospital, Edendale Hospital, Inkosi Albert Luthuli Central Hospital, Grey’s Hospital, King Edward VIII Hospital, RK Khan Hospital and Mahatma Gandhi Memorial Hospital. Children with suspected TBM were defined as having had CSF sent to the laboratory for Mycobacterium tuberculosis (Mtb) detection by microscopy and culture. Children ( 3 months to 15 years) with suspected TBM who presented to these hospitals from June 2010 to January 2014 inclusive were identified from the National Health Laboratory Service computerized records. Candidate clinical variables potentially predictive of TBM were identified from the published literature and included in a case report form (Fig., Supplemental Digital Content 1, http://links.lww.com/INF/C807). ${ }^{3,7,14,15,18}$ The case report forms were then completed using clinical information retrieved from the case notes of the identified children. Cases were defined as children with microbiologically confirmed TBM by CSF culture. The use of Xpert MTB/RIF on CSF samples had not been implemented in KZN during our study period. Controls were defined as children with suspected TBM, who were unlikely to have had TBM: Mtb not detected in the CSF by microscopy and culture; did not receive anti-tuberculous treatment; and did not have a poor outcome (no death or neurologic sequelae), or another CNS pathogen was isolated. Cases were matched with three controls for age, sex, ethnicity and geographical origin to maximize the power of the study. ${ }^{19}$ Cases and controls were randomly allocated into development (67\% of patients) and test groups (33\% of patients). The development group was used to identify the variables (with less than $20 \%$ missing data) that were most significantly predictive of TBM by univariate analysis. Analyses were performed using SPSS (Version 20.0.0.1, IBM Corporation). The significance level was set 
at 5\%. Continuous variables were dichotomized using Receiver Operator Characteristic (ROC) analyses to yield threshold values of maximum significance. Univariate and multivariate logistic regression were used to identify the most appropriate variables and the most efficient model. The decision tool was created using the most clinically independent variables from those identified in the univariate analysis. The most sensitive diagnostic threshold value for the tool was identified by ROC analysis, without compromising on specificity. Finally, the performance of the decision tool was evaluated on the test group of cases and controls.

All personal information regarding study participants was treated confidentially. The study received ethical approval from the Department of Health, KwaZulu-Natal (reference HRKM323/13), University of KwaZulu-Natal (reference BE334/13) and University of Liverpool (reference RETH000667).

\section{RESULTS}

During the study period 865 children met inclusion criteria for suspected TBM (Fig., Supplemental Digital Content 2, http://links.lww.com/INF/C808). TBM was microbiologically confirmed by CSF culture in 3\% (25/865). One case (1/25) was also identified by detection of acid-fast bacilli during CSF microscopy. No cases were detected by Xpert MTB/RIF which was not used in KZN during the study period. A CNS infection other than TBM was confirmed by culture and/or polymerase chain reaction in $6 \%$ (55/865). Clinical case notes were retrieved for $88 \%$ (22/25) of the children with microbiologically confirmed TBM. Drug susceptibility testing revealed multi-drug resistant (MDR) Mtb in 23\% (5/22) and extremely-drug resistant (XDR) Mtb in 9\% (2/22). The baseline characteristics, diagnosis and outcome of the 22 cases and 66 matched controls are displayed in Table 1. The median age of cases was 5.2 years (range: 5 months -13.3 years) and matched controls was 4.7 years (range: 4 months - 13.2 years). There 
were no significant differences between cases and matched controls with regards to age, sex, ethnicity, geographical origin, HIV status and whether a chest x-ray or extraneural imaging was performed. Cases were significantly more likely to have had neuroimaging performed than controls $(\mathrm{p}<0.001)$. The matched controls contained 6\% (4/66) with a CNS infection other than TBM, and in the rest no pathogen was isolated. Outcome was significantly poorer in terms of morbidity for cases than controls $(\mathrm{p}<0.001)$, though there was no significant difference in survival ( $\mathrm{p}=0.06$ ). Four cases who left hospital without a diagnosis were later confirmed to have TBM. Outcome data was available for two of these cases: both re-presented to hospital, were commenced on anti-tuberculous treatment and had severe neurological sequelae.

Children were randomly allocated into a 'development' (15 cases and 45 controls) or 'test' group (7 cases and 21 controls). The development group was used to identify variables predictive of TBM. Univariate analyses identified the yariables that differed significantly between cases and controls (Table 2). Continuous variables were transformed to dichotomous variables using ROC threshold values of maximum significance e.g. serum sodium $\leq 132 \mathrm{mmol} / \mathrm{L}$ and CSF protein $\geq 0.65 \mathrm{~g} / \mathrm{L}$ were found to be more predictive than standard laboratory reference ranges that define decreased serum sodium or raised CSF protein. Variables that were not significantly predictive of TBM included: seizures, fever; vomiting; persistent cough for more than 2 weeks; regular/close contact with someone with TB within last year; weight-for-age centile; irritability; neck stiffness; bulging fontanelle; HIV status; WHO HIV Clinical Stage; use of antiretroviral treatment (ART); time since initiation of ART; hemoglobin; peripheral white cell count; serum creatinine, CSF appearance; CSF polymorphonulcear cell count; and CSF erythrocyte count. Variables for which there were greater than $20 \%$ missing data were excluded: headache; photophobia; night sweats; Glasgow Coma Scale; papilledema; Mantoux result; serum glucose 
(thus CSF: serum glucose ratio); CSF opening pressure; chest x-ray; computed tomography (CT) head; extraneural imaging; and extraneural Mtb detection.

The clinical decision tool was modelled from the most independently predictive variables from Table 2. Backward regression identified co-dependent parameters. We retained the most significant parameters based on univariate analysis. Weighting variables based on their odds ratio in discriminating between cases and controls did not provide additional benefit to the model. Furthermore, ROC analysis identified that giving individual weightings for presence of abnormal posture, abnormal reflexes, increased tone and cranial nerve palsy, performed no better than asking whether 'any new focal deficit' was present. Similarly CSF lymphocytes and CSF protein were used in place of CSF white cell count, CSF glucose and CSF chloride. 'Abnormal behavior' was also discarded as it did not provide any additional value to the new models. There was insufficient data to include several variables previously recognized to add specificity to the diagnosis of TB (e.g. Mantoux, chest x-ray, extraneural Mtb detection and neuroimaging). The decision tool was summarized by the acronym 'CHILD TB LP' (Figure 1). A cut-off score of $\geq 4$ out of 9 gave optimum sensitivity (93\%) and specificity (89\%) on ROC analysis of the development group. Finally, the CHILD TB LP tool was assessed on the test group, in whom there was missing data for a median of 1 (range $0-4$ ) out of 9 variables. The CHILD TB LP tool performed with $100 \%$ sensitivity, $90 \%$ specificity and $93 \%$ accuracy in the test group.

\section{DISCUSSION}

We developed a rapid clinical decision tool to facilitate the accurate early diagnosis of TBM in children before CSF Mtb culture results become available. In keeping with previous studies, our data indicate a timely diagnosis of TBM is not always achieved through conventional diagnostic 
approaches, with 4 out of 22 children with culture proven TBM discharged from hospital without anti-tuberculous treatment before their diagnoses were confirmed. ${ }^{2,3,6,7}$

The CHILD TB LP decision tool is comprised of the most predictive, independent, highly documented and locally relevant variables. The tool's variables can be ascertained by historytaking or simple bedside clinical examination. It does not rely on tests that are not universally available across KZN such as neuroimaging or TB culture, which if depended upon can introduce unacceptable delays in the diagnosis and treatment of $\mathrm{TBM}^{20}{ }^{20}$ To our knowledge, there is only one previous study that developed a clinical decision tool to facilitate diagnosis of childhood TBM based on primary clinical data. ${ }^{15}$ The tool includes similar variables to CHILD TB LP such as illness length $>7$ days and any focal deficit. However this previous tool is arguably limited by the need to assess patients for optic atrophy, given the specialist training required to perform fundoscopy accurately. ${ }^{21}$

Neuroimaging is not required to make a diagnosis of TBM using our tool. Nevertheless, the value of neuroimaging to detect intra-cranial complications (such as tuberculomas and hydrocephalus) and to guide neurosurgical intervention among suspected TBM patients compelled us to include a prompt to perform neuroimaging in suspected TBM patients within our tool. $^{22,23}$

Given the significant number of drug-resistant cases in our cohort, we also included a prompt to remind users of the importance of microbiological testing for TB in other samples (e.g. sputum). Structuring our variables into the acronym CHILD TB LP may improve adoption of the tool by clinicians, as the user-friendliness of a clinical decision tool has been shown to influence the success of its implementation. ${ }^{24}$ 
Since the completion of our study, the use of Xpert MTB/RIF on extrapulmonary samples has been introduced across South African hospitals. The routine use of Xpert MTB/RIF has the potential to enable more rapid Mtb detection in CSF samples, and was recommended by the WHO in 2013. ${ }^{12}$ However, a Ugandan study demonstrated that large volume (median: $6 \mathrm{~mL}$, inter-quartile range: 4-10 mL) centrifuged CSF samples were required to achieve $72 \%$ sensitivity compared with a research case definition of TBM..$^{25}$ In practice, large CSF volumes are not always collected in children or infants, in part, because of concerns around safety. ${ }^{26}$ Furthermore, a meta-analysis of Xpert MTB/RIF in CSF samples demonstrated a pooled sensitivity of $79.5 \%$ (95\% confidence interval: $62.0 \%-90.2 \%$ ) with culture as the reference standard. ${ }^{12}$ Given the imperfect sensitivity of Xpert MTB/RIF and challenges surrounding sample collection, we would advocate our clinical decision tool should be assessed as an inexpensive adjunct to facilitate the accurate early diagnosis of TBM.

Apart from small sample size, a key limitation of our study is that our tool has been developed using retrospectively collected clinical data. We cannot confirm if the managing clinicians perceived the same level of risk of TBM among the cases and controls. This is potentially highlighted by significantly less neuroimaging undertaken in the control group. Furthermore, our study population was potentially limited by not including children who did not have CSF analysis for TB, but who may have been suffering from TBM. We also excluded children who were treated for TBM but did not have microbiologically confirmed TBM, to ensure that: i) cases were only children with a definite microbiological diagnosis of TBM; ii) controls were not biased by the potential confounder of having TBM that had not been microbiologically confirmed. 
Despite the considerable level of irretrievable data for some variables, there were no systematic differences in missing data between cases and controls except neuroimaging. Dependent variables were excluded based on our subjective assessment of clinical correlation, and the resulting combinations of variables were modelled to produce a decision tool with maximum efficiency. Therefore, by including clinically independent variables and excluding variables with considerable missing data, we were able to focus our novel decision tool on the most highly documented and clinically available variables.

The rate of microbiologically confirmed CNS infections other than TBM was only 6\% (55/865), which may reflect their low prevalence in our source population. However meningitis with CSF pleocytosis and no detectable pathogen was relatively more common among our control cohort $(14 \%, 9 / 66)$, potentially reflecting culture-negative bacterial meningitis, particularly as local guidelines recommend empiric pre-hospitalization intramuscular ceftriaxone in suspected meningitis. ${ }^{27}$

HIV-infection increases the risk of TBM and other forms of bacterial meningitis, but was not significantly predictive of TBM in our cohort, possibly reflecting the successful public sector rollout of ART across South Africa since 2004. ${ }^{28-30}$ In addition, our data did not demonstrate the previously reported predictive value of regular or close contact with a TB-infected adult. This may reflect poor knowledge or poor recall among historians or the successful implementation of household contact tracing and isoniazid preventative therapy. ${ }^{1,3,31}$ HIV-infected caregivers are commonly the household source of infection in childhood TB, and caregiver HIV status was significantly predictive of TBM in our cohort (independently of the child's HIV status). ${ }^{32}$ The inclusion of caregiver HIV status in our clinical decision tool might limit its applicability in settings of low HIV prevalence. HIV-exposed but uninfected children are at increased risk of 
severe infection compared with HIV-unexposed children, possibly as a result of increased pathogen exposure, feeding practices, poor vertical antibody acquisition and impaired innate and T-cell immunity. ${ }^{33-35}$

We propose that the CHILD TB LP clinical decision tool is tested prospectively in children with suspected CNS infection presenting to hospitals in similar settings. Given Xpert MTB/RIF's relatively low sensitivity for Mtb in CSF (particularly in low volume samples), our clinical decision tool may still assist rapid diagnosis of TBM in settings where Xpert MTB/RIF is available.

\section{CONFLICTS OF INTEREST AND SOURCES OF FUNDING}

The authors declare no conflict of interest. Dr. Anu Goenka was supported by a Royal College of Physicians Thomas Watts Eden Fellowship. The study was supported by the National Institute for Health Research Health Protection Research Unit (NIHR HPRU) in Emerging and Zoonotic Infections at the University of Liverpool in partnership with Public Health England (PHE) and Liverpool School of Tropical Medicine (LSTM). The views expressed are those of the author(s) and not necessarily those of the NHS, the NIHR, the Department of Health or Public Health England.

\section{CONTIBUTION STATEMENT}

AG, BD, TS and MG conceived the study. AG, KM, KS, PJ, RS and BD collected the data. AV assisted with the statistical analysis. All authors contributed to the manuscript and read the final version. The authors would also like to acknowledge the help of the secretaries and clinical record clerks involved in the study, as well as the staff of the National Health Laboratory Service, in particular Ms. Nombali Makhoba and Dr. Amanda Khumalo. 


\section{REFERENCES}

1. Yaramis A, Gurkan F, Elevli M, et al. Central nervous system tuberculosis in children: a review of 214 cases. Pediatrics. 1998;102:E49.

2. Lee LV. Neurotuberculosis among Filipino children: an 11 years experience at the Philippine Children's Medical Center. Brain Dev. 2000;22:469-474.

3. van Well GT, Paes BF, Terwee CB, et al. Twenty years of pediatric tuberculous meningitis: a retrospective cohort study in the western cape of South Africa. Pediatrics. 2009;123:e1-8.

4. Wolzak NK, Cooke ML, Orth H, van Toorn R. The changing profile of pediatric meningitis at a referral centre in Cape Town, South Africa. J Trop Pediatr. 2012;58:491-495.

5. Thwaites GE, van Toorn R, Schoeman J. Tuberculous meningitis: more questions, still too few answers. Lancet Neurol. 2013;12:999-1010.

6. Chiang SS, Khan FA, Milstein MB, et al. Treatment outcomes of childhood tuberculous meningitis: a systematic review and meta-analysis. Lancet Infect Dis. 2014;14:947-957. 7. Saitoh A, Pong A, Waecker NJ, Jr., Leake JA, Nespeca MP, Bradley JS. Prediction of neurologic sequelae in childhood tuberculous meningitis: a review of 20 cases and proposal of a novel scoring system. Pediatr Infect Dis J. 2005;24:207-212.

8. Thwaites GE, Tran TH. Tuberculous meningitis: many questions, too few answers. Lancet Neurol. 2005;4:160-170.

9. Stewart SM. The bacteriological diagnosis of tuberculous meningitis. J Clin Pathol. $1953 ; 6: 241-242$.

10. Thwaites GE, Chau TT, Farrar JJ. Improving the bacteriological diagnosis of tuberculous meningitis. J Clin Microbiol. 2004;42:378-379. 
11. Ho J, Marais BJ, Gilbert GL, Ralph AP. Diagnosing tuberculous meningitis - have we made any progress? Trop Med Int Health. 2013;18:783-793.

12. World Health Organization, 2013. Policy update: XpertMTB/RIF assay for the diagnosis of pulmonary and extrapulmonary TB in adults and children. Geneva: WHO.

13. Qin ZZ, Pai M, Van Gemert W, Sahu S, Ghiasi M, Creswell J. How is Xpert MTB/RIF being implemented in 22 high tuberculosis burden countries? Eur Respir J. 2015;45:549-554.

14. Andronikou S, Wilmshurst J, Hatherill M, VanToorn R. Distribution of brain infarction in children with tuberculous meningitis and correlation with outcome score at 6 months. Pediatr Radiol. 2006;36:1289-1294.

15. Kumar R, Singh SN, Kohli N. A diagnostic rule for tuberculous meningitis. Arch Dis Child. 1999;81:221-224.

16. Kalita J, Misra UK, Ranjan P. Predictors of long-term neurological sequelae of tuberculous meningitis: a multivariate analysis. Eur J Neurol. 2007;14:33-37.

17. Health Systems Trust, 2014. District Health Barometer 2013/14. Durban: HST.

18. Marais S, Thwaites G, Schoeman JF, et al. Tuberculous meningitis: a uniform case definition for use in clinical research. Lancet Infect Dis. 2010;10:803-812.

19. Gail M, Williams R, Byar DP, Brown C. How many controls? J Chronic Dis. 1976;29:723731.

20. Bhigjee AI. Use of the Xpert MTB/RIF assay in the diagnosis of tuberculous meningitis: a cautionary note. S Afr Med J. 2014;104:650.

21. Morad Y, Barkana Y, Avni I, Kozer E. Fundus anomalies: what the pediatrician's eye can't see. Int J Qual Health Care. 2004;16:363-365. 
22. Figaji AA, Fieggen AG. The neurosurgical and acute care management of tuberculous meningitis: evidence and current practice. Tuberculosis (Edinb). 2010;90:393-400.

23. Schoeman JF, Van Zyl LE, Laubscher JA, Donald PR. Serial CT scanning in childhood tuberculous meningitis: prognostic features in 198 cases. J Child Neurol. 1995;10:320-329. 24. Couto-Alves A, Wright VJ, Perumal K, et al. A new scoring system derived from base excess and platelet count at presentation predicts mortality in paediatric meningococcal sepsis. Crit Care. 2013;17:R68.

25. Bahr NC, Tugume L, Rajasingham R, et al. Improved diagnostic sensitivity for tuberculous meningitis with Xpert MTB/RIF of centrifuged CSF. Int J Tuberc Lung Dis. 2015;19:1209-1215. 26. Thwaites G, Fisher M, Hemingway C, et al. British Infection Society guidelines for the diagnosis and treatment of tuberculosis of the central nervous system in adults and children. $J$ Infect. 2009;59:167-187.

27. Department of Health South Africa, WHO Divsion of Child Health and Development and UNICEF, 2011. Integrated Management of Childhood Illness chart booklet. Pretoria: Department of Health, South Africa.

28. Hesseling AC, Westra AE, Werschkull H, et al. Outcome of HIV infected children with culture confirmed tuberculosis. Arch Dis Child. 2005;90:1171-1174.

29. McCormick DW, Wilson ML, Mankhambo L, et al. Risk factors for death and severe sequelae in Malawian children with bacterial meningitis, 1997-2010. Pediatr Infect Dis J. 2013;32:e54-61.

30. April MD, Wood R, Berkowitz BK, et al. The survival benefits of antiretroviral therapy in South Africa. J Infect Dis. 2014;209:491-499. 
31. Ayieko J, Abuogi L, Simchowitz B, Bukusi EA, Smith AH, Reingold A. Efficacy of isoniazid prophylactic therapy in prevention of tuberculosis in children: a meta-analysis. $B M C$ Infect Dis. 2014;14:91.

32. Lawn SD, Bekker LG, Middelkoop K, Myer L, Wood R. Impact of HIV infection on the epidemiology of tuberculosis in a peri-urban community in South Africa: the need for agespecific interventions. Clin Infect Dis. 2006;42:1040-1047.

33. de Moraes-Pinto MI, Almeida AC, Kenj G, et al. Placental transfer and maternally acquired neonatal IgG immunity in human immunodeficiency virus infection. J Infect Dis. 1996;173:1077-1084.

34. Kuhn L, Kasonde P, Sinkala M, et al. Does severity of HIV disease in HIV-infected mothers affect mortality and morbidity among their uninfected infants? Clin Infect Dis. 2005;41:16541661.

35. McNally LM, Jeena PM, Gajee K, et al. Effect of age, polymicrobial disease, and maternal HIV status on treatment response and cause of seyere pneumonia in South African children: a prospective descriptive study. Lancet. 2007;369:1440-1451. 


\section{FIGURE LEGENDS}

Figure 1. A novel rapid clinical decision tool to identify TBM: CHILD TB LP SUPPLEMENTARY DIGITAL CONTENT

Figure, Supplementary Digital Content 1. Case report form

Figure, Supplementary Digital Content 2. Selection of cases and matched controls 
Table 1. Baseline characteristics, diagnosis and outcome

\begin{tabular}{|c|c|c|c|c|}
\hline Variable & $\begin{array}{c}\text { Cases } \\
\text { Confirmed } \\
\text { TBM } \\
\mathrm{n}=22\end{array}$ & $\begin{array}{c}\text { Controls } \\
\text { Unlikely } \\
\text { TBM } \\
\mathrm{n}=66\end{array}$ & $\begin{array}{l}\text { Pearson } \\
\text { Chi- } \\
\text { Squared } \\
\text { (df) }\end{array}$ & $p$-value \\
\hline $\begin{array}{ll} & >3 \text { months old to }<1 \text { year old } \\
\text { Age }^{\star} \quad>1 \text { year old to }<5 \text { years old } \\
& >5 \text { years old to }<15 \text { years old }\end{array}$ & $\begin{array}{c}2(9 \%) \\
8(36 \%) \\
12(55 \%)\end{array}$ & $\begin{array}{c}6(9 \%) \\
28(42 \%) \\
32(49 \%)\end{array}$ & $0.27(2)$ & 0.874 \\
\hline $\begin{array}{ll}\text { Sex } & \text { Male } \\
& \text { Female }\end{array}$ & $\begin{array}{l}11(50 \%) \\
11(50 \%)\end{array}$ & $\begin{array}{l}33(50 \%) \\
33(50 \%)\end{array}$ & $0.00(1)$ & 1.000 \\
\hline $\begin{array}{ll}\text { Ethnicity }^{*} & \begin{array}{l}\text { Black } \\
\text { Indian }\end{array}\end{array}$ & $\begin{array}{c}21(95 \%) \\
1(5 \%)\end{array}$ & $\begin{array}{c}63(95 \%) \\
3(5 \%)\end{array}$ & 0.00 (1) & 1.000 \\
\hline $\begin{array}{ll}\text { Geographical origin* } & \begin{array}{l}\text { Durban area } \\
\text { Pietermaritzburg area }\end{array}\end{array}$ & $\begin{array}{l}17(77 \%) \\
5(23 \%)\end{array}$ & $\begin{array}{l}50(76 \%) \\
16(24 \%)\end{array}$ & $0.02(1)$ & 0.885 \\
\hline $\begin{aligned} \text { HIV status } & \text { Positive } \\
\text { HIV exposed awaiting HIV test result } & \text { Negative } \\
& \text { Unknown }\end{aligned}$ & $\begin{array}{c}11(50 \%) \\
0 \\
9(41 \%) \\
2(9 \%)\end{array}$ & $\begin{array}{c}23(35 \%) \\
2(3 \%) \\
30(45 \%) \\
11(17 \%)\end{array}$ & 2.37 (3) & 0.500 \\
\hline Lumbar puncture $\begin{array}{l}\text { Performed } \\
\text { Not Performed }\end{array}$ & $\begin{array}{c}22(100 \%) \\
0\end{array}$ & $\begin{array}{c}66(100 \%) \\
0\end{array}$ & $0.00(1)$ & 1.000 \\
\hline Neuroimaging $\begin{array}{l}\text { Performed } \\
\text { Not Performed }\end{array}$ & $\begin{array}{c}22(100 \%) \\
0\end{array}$ & $\begin{array}{l}25(38 \%) \\
41(62 \%)\end{array}$ & 25.59 (1) & $<0.001$ \\
\hline $\begin{array}{ll} & \text { Performed } \\
\text { Chest X-Ray } & \text { Not Performed } \\
& \text { Not Recorded }\end{array}$ & $\begin{array}{c}13(59 \%) \\
7(32 \%) \\
2(9 \%)\end{array}$ & $\begin{array}{c}37(56 \%) \\
28(42 \%) \\
1(2 \%)\end{array}$ & 3.27 (2) & 0.195 \\
\hline $\begin{array}{ll}\text { Extraneural imaging for TB } & \begin{array}{l}\text { Performed } \\
\text { Not Performed }\end{array}\end{array}$ & $\begin{array}{c}4(18 \%) \\
18(82 \%)\end{array}$ & $\begin{array}{c}6(9 \%) \\
60(91 \%)\end{array}$ & $1.35(1)$ & 0.245 \\
\hline $\begin{array}{ll} & \text { TBM } \\
& \text { Viral infection } \\
& \text { Suspected or proven bacterial infection } \\
& \text { Meningitis with CSF pleocytosis and no detectable pathogen } \\
& \text { Acute febrile encephalopathy of unknown cause } \\
\text { Final } & \text { Febrile seizure } \\
\text { clinician } & \text { Disseminated TB } \\
\text { diagnosis } & \text { Pulmonary TB } \\
\text { Pyogenic bacterial meningitis } \\
\text { Cerebral malaria } \\
\text { Headache of unknown cause } \\
\text { Guillain-Barré Syndrome } \\
\text { Malignancy } \\
\text { Stroke }\end{array}$ & $\begin{array}{c}18(82 \%) \\
0 \\
1(5 \%) \\
0 \\
3(13 \%) \\
0 \\
0 \\
0 \\
0 \\
0 \\
0 \\
0 \\
0 \\
0\end{array}$ & $\begin{array}{c}0 \\
16(24 \%) \\
10(15 \%) \\
9(13 \%) \\
4(6 \%) \\
6(9 \%) \\
5(8 \%) \\
5(7 \%) \\
4(6 \%) \dagger \\
2(3 \%) \\
2(3 \%) \\
1(2 \%) \\
1(2 \%) \\
1(2 \%)\end{array}$ & 74.01 (13) & $<0.001$ \\
\hline Glasgow Outcome Score $^{1 /}$ Very Poor Outcome & 9 (41\%) & $3(4 \%)$ & 53.39 (3) & $<0.001$ \\
\hline
\end{tabular}




\begin{tabular}{|cl|c|c|c|c|}
\hline (at discharge) & Poor Outcome & $2(9 \%)$ & $1(2 \%)$ & \\
& No-Mild Disability & Not Recorded & $2(9 \%)$ & $60(91 \%)$ \\
$9(41 \%)$ & $2(3 \%)$ & \\
\hline \multirow{2}{*}{ Survival } & Died & $3(14 \%)$ & $2(3 \%)$ & $3.46(1)$ & 0.062 \\
& Survived to Discharge & $19(86 \%)$ & $64(97 \%)$ & \\
\hline
\end{tabular}

${ }^{*}$ Baseline characteristic matched between cases and controls + Comprising of: pneumococcal meningitis ( 3 cases), meningococcal meningitis ( 1 case)

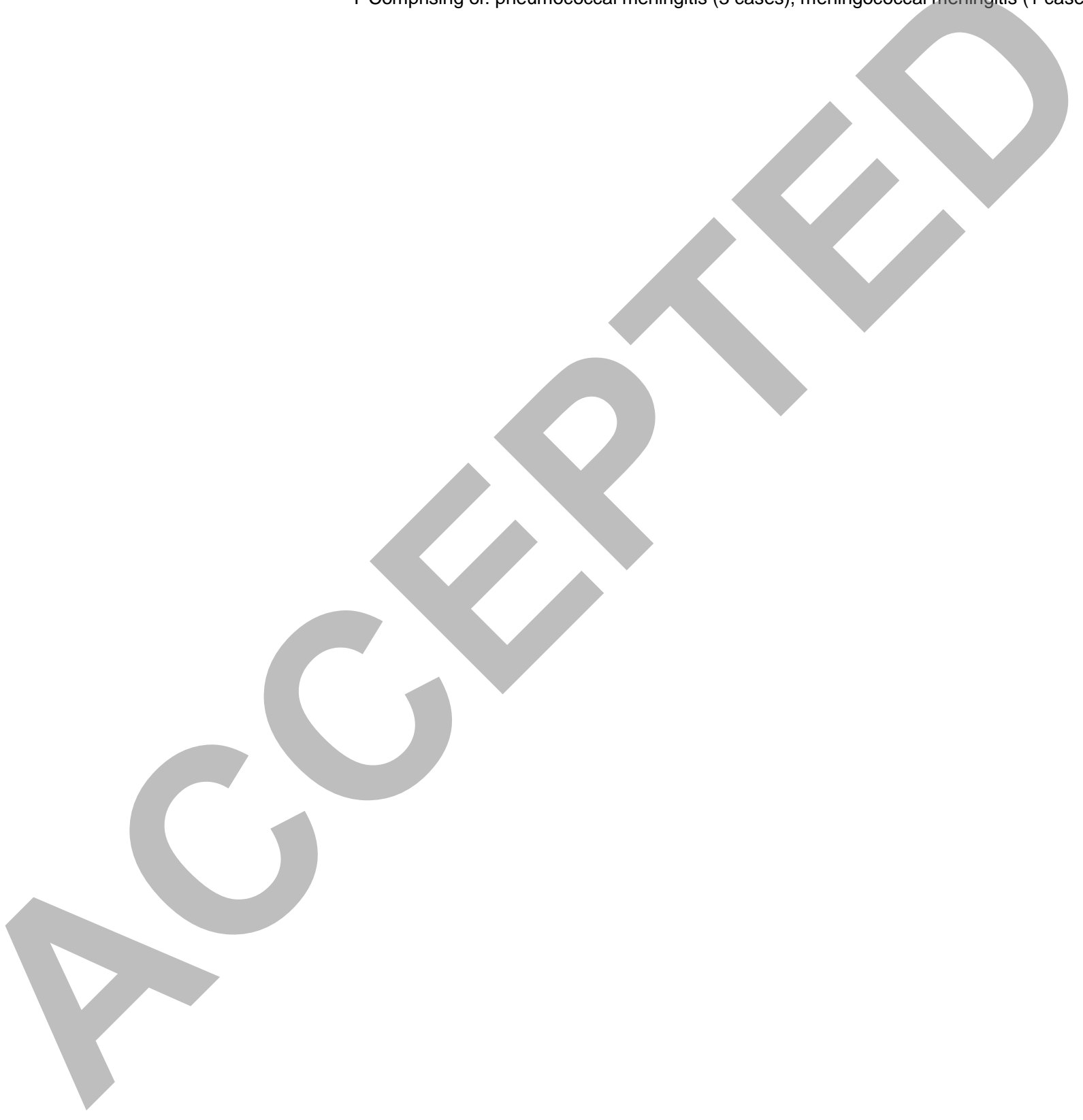


Table 2. Univariate analysis of variables significantly predictive of TBM

\begin{tabular}{|c|c|c|c|c|c|}
\hline Variable & $\begin{array}{c}\text { Cases } \\
\text { Confirmed TBM } \\
n=15\end{array}$ & $\begin{array}{c}\text { Controls } \\
\text { Unlikely TBM } \\
\qquad n=45\end{array}$ & $\begin{array}{l}\text { Odds Ratio* }^{*} \\
\text { (95\% confidence } \\
\text { interval) }\end{array}$ & p-value & $\begin{array}{c}\text { Missing Data }+ \\
n=60\end{array}$ \\
\hline History of poor weight gain & $10(71 \%)$ & $7(16 \%)$ & $13.2(3.2-54.30)$ & $<0.001$ & $2(3.3 \%)$ \\
\hline Fatigue/reduced playfulness & $11(85 \%)$ & $17(41 \%)$ & $7.8(1.5-39.6)$ & 0.010 & $6(10.0 \%)$ \\
\hline History of altered consciousness & $12(80 \%)$ & $21(47 \%)$ & $4.5(1.1-18.4)$ & 0.036 & $0(0 \%)$ \\
\hline Caregiver HIV infected & $10(91 \%)$ & $18(47 \%)$ & $11.1(1.3-95.6)$ & 0.014 & $11(18.3 \%)$ \\
\hline Abnormal behavior & $6(55 \%)$ & $6(13 \%)$ & $7.8(1.8-33.8)$ & 0.008 & $4(6.7 \%)$ \\
\hline Any new focal deficit & $11(73 \%)$ & $5(11 \%)$ & $22.0(5.0-96.1)$ & $<0.001$ & $0(0 \%)$ \\
\hline Abnormal posture & $11(73 \%)$ & $5(11 \%)$ & $22.0(5.0-96.1)$ & $<0.001$ & $0(0 \%)$ \\
\hline Abnormal reflexes & $9(60 \%)$ & $6(14 \%)$ & $9.5(2.4-36.5)$ & 0.001 & $1(1.7 \%)$ \\
\hline Cranial nerve palsy & $6(50 \%)$ & $2(4 \%)$ & $21.5(4.0-123.5)$ & $<0.001$ & $3(5.0 \%)$ \\
\hline Increased tone & $10(67 \%)$ & $5(11 \%)$ & $15.6(3.7-64.6)$ & $<0.001$ & $1(1.7 \%)$ \\
\hline $\begin{array}{l}\text { Illness length > 7days } \\
\text { Median (days) }\end{array}$ & $\begin{array}{c}7(58 \%) \\
12\end{array}$ & $5(16 \%)$ & $8.96(2.0-39.6)$ & 0.004 & $11(18.3 \%)$ \\
\hline $\begin{array}{l}\text { Serum sodium } \leq 132 \mathrm{mmol} / \mathrm{L} \\
\text { Median }(\mathrm{mmol} / \mathrm{L})\end{array}$ & $10(83 \%)$ & $4(9 \%$ & $50.0(8.0-312.7)$ & $<0.001$ & $4(6.7 \%)$ \\
\hline $\begin{array}{l}\text { CSF white cell count } \geq 18 \text { cells } \times 10^{6} / \mathrm{L} \\
\text { Median (cells } \times 10^{6} / \mathrm{L} \text { ) }\end{array}$ & $9(60 \%)$ & $7(100)$ & $7.7(2.1-28.7)$ & 0.002 & $2(3.3 \%)$ \\
\hline $\begin{array}{l}\text { CSF lymphocytes } \geq 10 \text { cells } \times 10^{6} / \mathrm{L} \\
\text { Median (cells } \times 10^{6} / \mathrm{L} \text { ) }\end{array}$ & $9(60 \%)$ & $\begin{array}{c}8(18 \%) \\
0\end{array}$ & $6.6(1.8-23.7)$ & 0.006 & $2(3.3 \%)$ \\
\hline $\begin{array}{l}\text { CSF protein } \geq 0.65 g / L \\
\text { Median }(g / L)\end{array}$ & $\begin{array}{l}11(73 \%) \\
0.85\end{array}$ & $\begin{array}{c}6(14 \%) \\
0.20\end{array}$ & $17.4(4.2-72.9)$ & $<0.001$ & $1(1.7 \%)$ \\
\hline $\begin{array}{l}\text { CSF glucose } \leq 2.3 \mathrm{mmol} / \mathrm{L} \\
\text { Median }(\mathrm{mmol} / \mathrm{L})\end{array}$ & $\begin{array}{c}7(50 \%) \\
1.6\end{array}$ & $\begin{array}{c}7(16 \%) \\
3.6\end{array}$ & $5.4(1.4-20.4)$ & 0.009 & $1(1.7 \%)$ \\
\hline $\begin{array}{l}\text { CSF chloride } \leq 119 \mathrm{mmol} / \mathrm{L} \\
\text { Median }(\mathrm{mmol} / \mathrm{L})\end{array}$ & $\begin{array}{c}10(71 \%) \\
110\end{array}$ & $\begin{array}{c}14(36 \%) \\
121\end{array}$ & $5.2(1.4-19.5)$ & 0.014 & $3(5.0 \%)$ \\
\hline
\end{tabular}

*Odds ratio calculated from available data and significance determined using Fisher's exact test; †Missing data calculated using number missing fields for each variable among development group of cases and controls 
Figure 1. A novel rapid clinical decision tool to identify TBM: CHILD TB LP

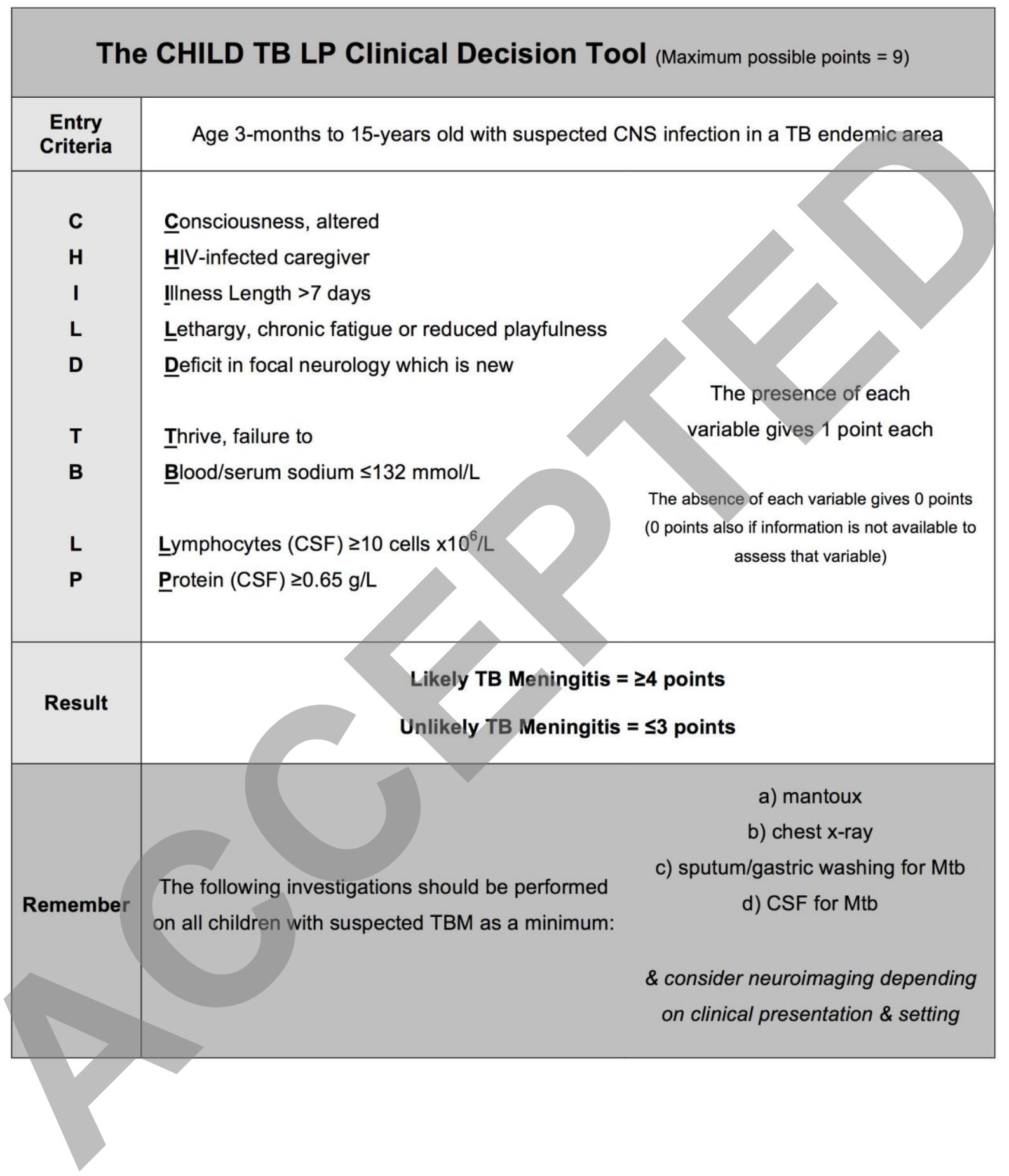

